\title{
Analysis on the Difference of Energy Evolution in the Process of Energy Storage Failure of Strong Coal Rush Rock Samples under Different Adaptive Modification Regulation Measures
}

\author{
Fangfang Zhang \\ School of Architecture and Surveying Engineering, Shanxi Datong University, Datong, Shanxi 037003, China \\ Correspondence should be addressed to Fangfang Zhang; 1983191616@qq.com
}

Received 7 August 2021; Revised 26 October 2021; Accepted 2 November 2021; Published 7 January 2022

Academic Editor: Shaofeng Wang

Copyright (c) 2022 Fangfang Zhang. This is an open access article distributed under the Creative Commons Attribution License, which permits unrestricted use, distribution, and reproduction in any medium, provided the original work is properly cited.

\begin{abstract}
Current energy to "release" after accumulating + first for the mechanism of rock bursts occurred in analysis of the strategy is accepted by many scholars, based on the existing means of prevention and control of percussive ground pressure, from the angle of the prevention and control of design of the mechanism of impact ground pressure energy regulation, namely, "weakened after the first release +" softened water injection measures and "lead after the first release +" drilling pressure relief measures, for the study of mining under the action of a strong shock tendentiousness rock energy regulatory mechanism; based on rock mechanics experiment, the analysis under different modification measures should be variant energy storage mechanisms of induced damage evolution of rock energy. The mechanism of energy evolution in the modification of strong bursting liability roof rock is revealed. The results show that different modification regulation measures can effectively change the physical and mechanical parameters of target rock samples and realize "hard rock softening or soft rock hardening." Samples under different modification measures are classified as initial consolidation stage, elastic stage, stage of plastic deformation, yield failure stage, and late stage, the energy evolution is roughly the same as the sample complete natural condition, but the yield failure stage and the destruction of late stage have an obvious difference, which provides favorable conditions for impact ground pressure to prevent. With the help of three characteristic energy indexes of total strain, elastic strain energy, and dissipative strain energy of rock samples, the evolution law of energy indexes under different modification control measures is analyzed. The index of elastic energy consumption ratio is introduced as a precursor feature of rock instability and failure, which indicates the rock impact tendency to a certain extent. The energy regulation mechanisms of "first release+then weakening" water injection softening measures and "first release+then guidance" drilling pressure relief measures are explained theoretically, respectively. However, we should focus on the defects of the corresponding control measures and finally try to make a reasonable combination of different modification measures. Finally, the gradient pressure relief scheme should be considered in order to avoid large stress drop caused by large-scale pressure relief in the region and aggravate the instability of rock mass. The instability of rock mass is further aggravated.
\end{abstract}

\section{Introduction}

The rapid development of society cannot be separated from the drive of energy, and coal, as the cornerstone of China's current energy, is still in the dominant position of energy [1]. After the coal resources enter deep mining, due to the special environment of "three high and one disturbance," the phenomenon of dynamic disaster inevitably occurs, which seriously threatens the mining and related engineering construction in China, among which the accidents represented by rock burst are frequent and have a significant influence. Domestic and foreign researchers have also conducted extensive research on it and put forward a variety of academic views and gradually refined the mechanism of ground pressure impact disaster [2]. At present, on the basis of a large number of engineering practice, a relatively complete system of impingement technology is being explored, but because of the complexity of the formation 
mechanism of impact ground pressure and other factors that still need to be discussed, especially in deep coal mining, there is an urgency and necessity for safe and effective resources to achieve the depth development and maintenance of underground space which has important scientific significance and practical significance.

Stress concentration leads to energy focus, and the existence of weak surface is a prerequisite for the formation of rock burst [3-5]. Because of the complexity of rock burst mechanism, it is still difficult to put forward very effective and reliable measures at this stage. With the continuous optimization of various pressure relief measures in routine engineering practice, many empirical parameters have been formed to guide the prevention and control of rock burst. The research in this paper focuses on two commonly used pressure relief measures, involving water injection softening and large diameter pressure relief drilling, and further reveals the specific modification and regulation mechanism, which can guide the determination of existing empirical parameters and ensure the accuracy of engineering scale to prevent and control rock burst. Considering that there are many disaster-causing mechanisms of rock burst, this paper only discusses strain-type rock burst. In order to better explain the energy regulation mechanism of rock burst, this paper takes different in situ modification methods (water injection softening and borehole pressure relief) as examples to carry out experiments. Through two parallel test ideas, i.e., drilling with different water content and different pore diameters, the mechanical characteristics and parameters of coal and rock samples under different modified conditions under single bearing load are analyzed by means of the indoor uniaxial compression test. By analyzing the influence of different modification states on the input total energy, releasable elastic strain energy and dissipation energy of coal and rock samples during single bearing loading, the energy regulation mechanism is obtained. The research results have important theoretical value and engineering significance for understanding the damage energy evolution mechanism and energy regulation mechanism of coal and rock mass in different modified states and improving the rock energy theory and artificial induced regulation dynamic disaster theory.

\section{Modification Theory}

At present, in the method of in situ modification and the control mechanism, the main control method of rock burst is to reduce the strength of coal and rock mass by water injection to play the role of pressure relief. Blasting consumes the total energy after the start of rock burst, reduces the energy release speed, and thus, reduces the danger degree of rock burst; large-diameter hollow holes can reduce the accumulation of elastic energy of rock mass above and around the roadway and reduce the regional impact risk. The mining layout is adjusted to increase the energy dissipation, energy -absorption, and antipunching support of the anchor cable and bracket and fill control roof deformation and energy accumulation and release [7-9].
Based on the analysis of the formation mechanism of rockburst, many methods mentioned above have played an effective role in the engineering practice of rockburst prevention and control. Numerous studies can show that these research methods only regulate energy, but there is no more involvement in the coupling relationship between prevention and control methods and energy distribution; in addition, many analysis methods lack a strong theoretical basis, and the coal mine field practice measures tend to rely more on experience to determine the specific control parameters [10]. Considering the feasibility of carrying out research work, it is not at the scene to carry out the modification measures of mechanism analysis condition; therefore, the actual working condition of each under the modification measures is simplified to carry out the indoor modification experiments, and the corresponding variant energy storage mechanism of evolution of various control measures was induced damage energy gap analysis so as to provide theoretical basis for field modification measures $[11,12]$.

2.1. Description and Preparation of Rock Samples. The sampling sites of rock samples used in this experiment are all taken from W1123 working face of Kuangou Coal Mine of Shenxin Company. According to relevant sampling requirements, the roof shall be sampled in the direction perpendicular to the joint plane of coal and rock strata behind the support of the working face. In this paper, sandstone is acquired, and it will be treated by subsequent standards. Its specification is about a cube with a side length of $300 \mathrm{~mm}$. However, according to the national standard, the bending energy index of coal seam roof in Kuangou Coal Mine is $177.67 \mathrm{~kJ}$, which is greater than $120 \mathrm{~kJ}$, so it is determined that the coal seam roof is a rock stratum with strong impact tendency. At the same time, according to ISRM test standard, in order to facilitate subsequent test operation, the rock sample was processed into a $70 \mathrm{~mm} \times 70 \mathrm{~mm} \times 70 \mathrm{~mm}$ cube rock sample with smooth surface and no obvious cracks. The cut argillite siltstone was polished with fine sandpaper to ensure that the error was allowed.

At the same time, the microstructure of rock samples were observed by means of scanning electron microscopy (SEM), and the specific scanning electron microscopy results of rock samples are shown in Figure 1. The results show that the structure of the rock sample is dense, and the particles grow in the pore by means of a bridge, forming a network of filamentous and hair-like strands. When the quartz grains were multiplied, the crystal structure of long and regular pattern could be seen, and a large number of plate-like kaolinite and filamentous illite were distributed on the grain surface. According to several groups of scanning electron microscope without magnification, it was judged to be hard rock layer.

In order to approximate the real engineering environment as much as possible, this paper takes different in situ modification methods as examples, involving three methods of water injection softening, large diameter pressure relief drilling, and filling. 


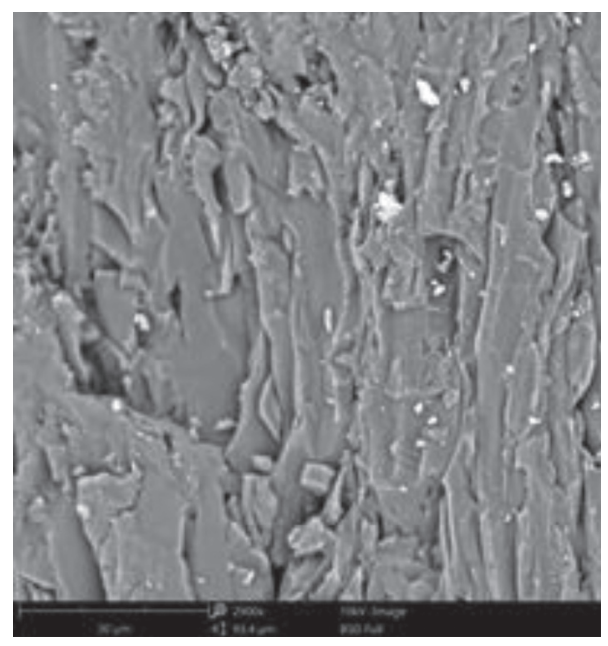

FIGURE 1: SEM diagram of rock samples.

2.1.1. Water Injection Softening Regulation (Different Water Content). In order to simulate the background of water injection and softening engineering, coal and rock samples with different water-bearing conditions were artificially set by soaking in a laboratory environment. In order to avoid interference from other factors, the sampled coal and rock samples are naturally air-dried for 24 hours and are defined as the natural state, which is approximately considered to have the same moisture content under the same state. In addition, according to the law of water absorption and water loss, the coal samples of less than or greater than the natural state were obtained by drying and soaking, respectively.

The specific water-bearing state treatment of coal and rock samples is as follows: (1) drying state: the samples were placed in an electric blast drying oven at $105^{\circ} \mathrm{C}$ for $48 \mathrm{~h}$; (2) saturation state: the specimen is put into the flume by the free immersion method, and the water is injected to $1 / 4$ of the height of the specimen and then injected to $1 / 2$ and $3 / 4$ of the height of the specimen every $2 \mathrm{~h}$. All the specimens are immersed after $6 \mathrm{~h}$, and the surface moisture is wiped off after $48 \mathrm{~h}$. The serial numbers and different water-bearing states of the samples are shown in Table 1.

\subsubsection{Pressure Relief Control of Borehole (with Different} Diameters). In this paper, in order to simulate the engineering background of borehole pressure relief and to further compare the difference of pressure relief effect of rock mass with different pore sizes, rock sample specimens with different pore sizes were artificially set through boreholes in the laboratory environment.

Because of bearing hole and the sample in the course of boundary effect, in order to further reduce the influence of boundary effect on the test result and according to the theory of related academic research and some experience conclusion, general border size is more than 5 times the radius of the hole, so the two different test diameters of holes were set up as a different hole size sample through state; namely, the borehole radius is set to $r_{1}=5 \mathrm{~mm}$ and $r_{2}=8 \mathrm{~mm}$. The serial number of the sample and different drilling states are shown in Table 2.
2.2. Test Equipment and Methods. This test relies on the selfbuilt comprehensive test system, which is coordinated and coordinated by the loading control system, strain analysis system, and video synchronous acquisition system, respectively. The loading control system is implemented by the RMT-150B Rock Mechanics testing machine institute (Wuhan Institute of Rock and Soil Mechanics, Chinese Academy of Sciences); the strain analysis system is implemented by the DH3823 distributed signal test and analysis system (Donghua Testing Technology Co., LTD.), and the video synchronous acquisition system is implemented by using the whole-process video capture instrument. In order to ensure that the rock sample is not broken suddenly, the test is conducted to load the rock sample stably by controlling the stress, with the loading rate constant at $0.2 \mathrm{kN} / \mathrm{s}$. The test monitoring software can automatically collect and timely process the test data, display the stress-displacement curve, stress-time curve, and disshift-time curve, etc. The comprehensive test system of rock mechanics is shown in Figure 2. After a series of pretreatments, the photos of rock samples are shown in Figure 3.

\section{Mechanical Properties of Bearing Rock Samples with Different Modification Regulation Measures}

3.1. Stress-Strain Curves of Bearing Specimens with Different Modification Regulation Measures. In this test, uniaxial compression tests were conducted on rock samples with strong bursting liability under different modification regulation measures, and mechanical parameters were processed and counted, as shown in Table 3 .

In order to compare the differences of different modified measures, this paper analyzed the natural state of the typical bearing rock stress-strain entire process curve; as shown, the second is based on the practical engineering background, to differentiate the following 3 different typical load samples before and after the modification measures stress-strain entire process curve for concrete comparative analysis. 
TABLe 1: Sample number and moisture content in each state.

\begin{tabular}{lccc}
\hline State of the specimens & The sample name & Specimen number & Average moisture content (\%) \\
\hline Natural state & Rock sample & $R_{0-1,2,3}$ & 0.00 \\
Dry state & Rock sample & $R_{1-1,2,3}$ & 2.41 \\
Saturated state & Rock sample & $R_{2-1,2,3}$ & 3.83 \\
\hline
\end{tabular}

TABLE 2: Sample number and drilling parameters of each state.

\begin{tabular}{lccc}
\hline State of the specimens & The sample name & Specimen number & Drilling parameters \\
\hline Small diameter through state & Rock sample & $R_{3-1,2,3}$ & $r_{1}=5 \mathrm{~mm}$ \\
Large diameter through state & Rock sample & $R_{4-1,2,3}$ & $r_{2}=8 \mathrm{~mm}$ \\
\hline
\end{tabular}

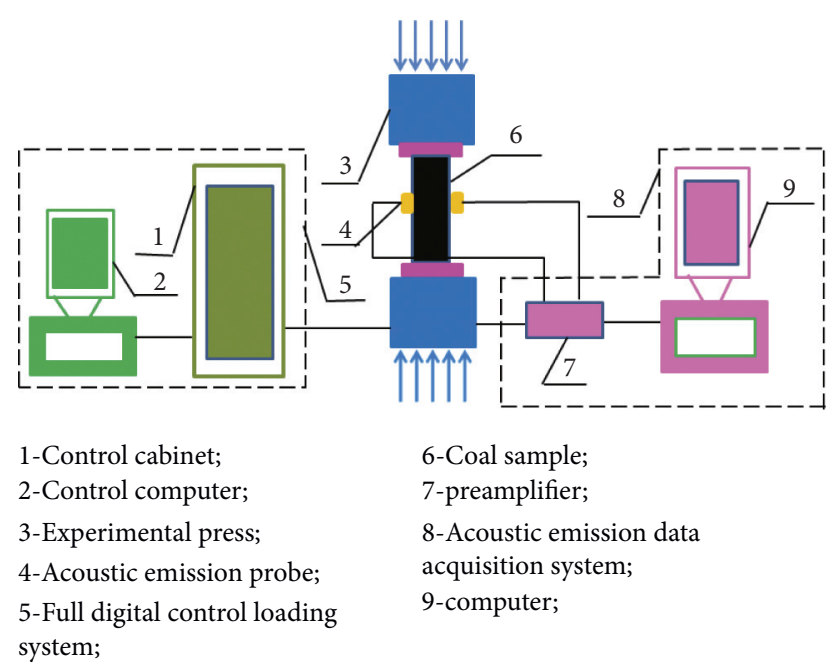

Figure 2: RMT integrated rock mechanics test system.

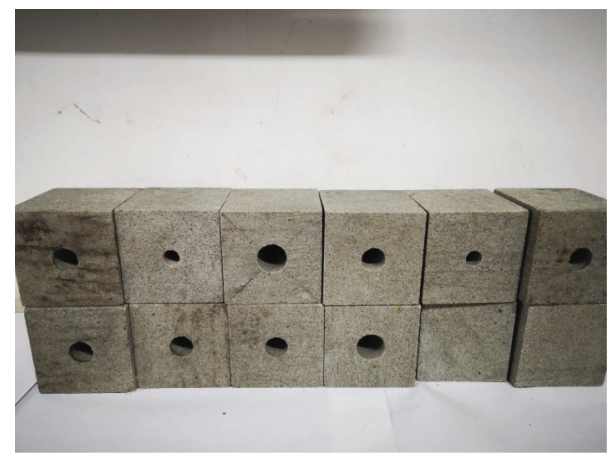

Figure 3: Actual pretreatment of rock samples.

3.1.1. Typical Natural State. The prepeak stress-strain curves of rock samples in uniaxial compression tests under different modification regulation measures have good similarity, while the postpeak stress-strain curves have an obvious difference. All rock samples underwent initial compaction, elastic deformation, plastic deformation, yield failure, and late failure stages.

3.1.2. Waterflood Softening Regulation. Figure 4 shows different water softening control (change of moisture content) states of the rock stress-strain curve, and the test results show that different water softening regulations of rock sample under a uniaxial compression test before the peak stress-strain curve have good similarity and after the peak have different stress-strain curves, peak strain ranges, and moisture content after a positive correlation.

When the average water content of the rock sample is 0 , $2.41 \%$, and $3.83 \%$, the average peak strength is $44.56 \mathrm{MPa}$, 28.20 $\mathrm{MPa}$, and 22.07 $\mathrm{MPa}$, respectively. The average peak strain is $0.02564,0.02127$, and 0.02120 , respectively. The average elastic modulus was $3.56 \mathrm{GPa}, 2.42 \mathrm{GPa}$, and $1.79 \mathrm{GPa}$, respectively. Compared with the completely dry rock samples, the average peak strength decreased by 
TABLE 3: Average mechanical parameters of rock samples with strong bursting liability under different modification states.

\begin{tabular}{lcccccc}
\hline $\begin{array}{l}\text { Corresponding working } \\
\text { condition }\end{array}$ & $\begin{array}{c}\text { State of the } \\
\text { specimens }\end{array}$ & Processing state & $\begin{array}{c}\text { Specimen } \\
\text { number }\end{array}$ & $\begin{array}{c}\text { Mean peak } \\
\text { intensity/MPa }\end{array}$ & $\begin{array}{c}\text { Mean peak } \\
\text { strain }\end{array}$ & $\begin{array}{c}\text { Mean modulus of } \\
\text { elasticity/GPa }\end{array}$ \\
\hline Blank test & Natural state & Blank untreated & $\mathrm{R}_{0-1,2,3}$ & 28.20 & 0.02127 & 2.42 \\
\hline Water softening & $\begin{array}{c}\text { Dry state } \\
\text { Saturated state }\end{array}$ & $\begin{array}{c}\text { Complete drying } \\
\text { Full water treatment }\end{array}$ & $\begin{array}{c}\mathrm{R}_{1-1,2,3} \\
\mathrm{R}_{2-1,2,3}\end{array}$ & 44.56 & 0.02564 & 3.56 \\
\hline \multirow{2}{*}{ Pressure relief hole } & $\begin{array}{c}\text { Well versed in } \\
\text { state }\end{array}$ & $\begin{array}{c}\text { Small-diameter drilling } \\
\text { treatment }\end{array}$ & $\mathrm{R}_{3-1,2,3}$ & 25.06 & 0.02120 & 1.79 \\
\hline & $\begin{array}{c}\text { Well versed in } \\
\text { state }\end{array}$ & $\begin{array}{c}\text { Treatment of large- } \\
\text { diameter drilling holes }\end{array}$ & $\mathrm{R}_{4-1,2,3}$ & 16.57 & 0.01969 & 0.86 \\
\hline
\end{tabular}

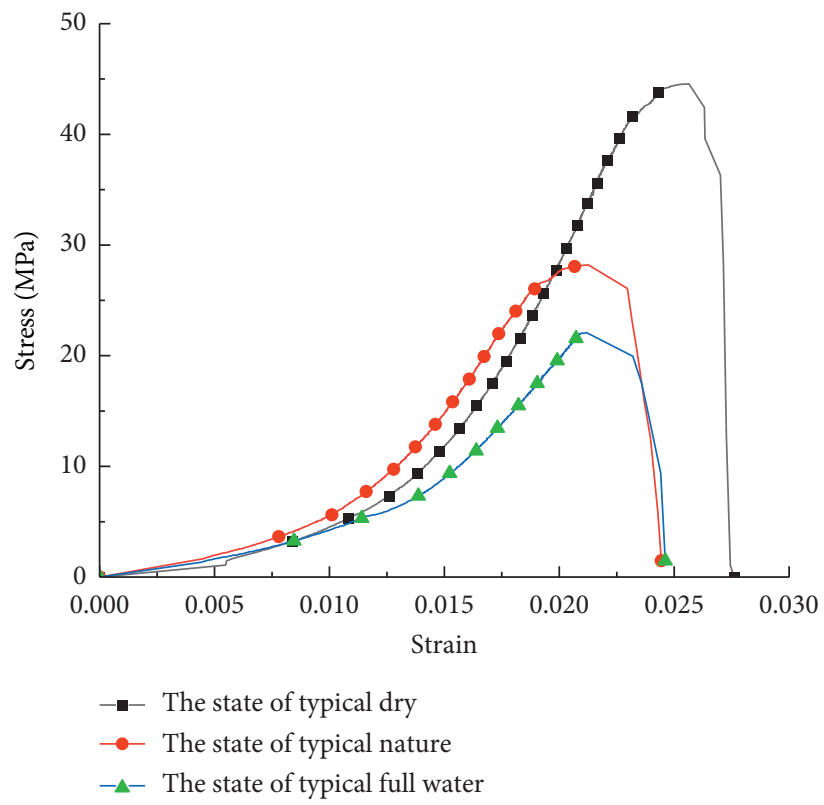

FIgURE 4: Stress-strain curves of rock samples in different water-bearing states.

$36.7 \%$ and $50.5 \%$, respectively. The average peak strain decreased by $17.0 \%$ and $17.3 \%$, respectively. The average modulus of elasticity decreased by $32.0 \%$ and $49.7 \%$, respectively.

The comparative test results show that, with the increase of water content, peak strength, peak strain, and elastic modulus of rock samples decrease, but the amplitude decreases significantly with the increase of water content.

With the increase of water content, the stress-strain curve of rock sample in the uniaxial compression test has an overall trend of left-shift compression. The reason for the crack in water molecules is the weak cohesion between particles, which leads to rock softening and further reduces the peak strength and elastic modulus of the rock sample; macroperformance for the overall mechanical properties decreased, but due to the particularity of hard rock, it has maintained the brittle failure properties, so the peak strain has a negative correlation, and as the moisture content increases, the peak strain ranges after further increase, characterized by certain ductility; in addition, with the increase of moisture content, the mechanical parameters of the reduction were significantly reduced.
3.1.3. Borehole Pressure Relief Control. Figure 5 shows different drilling pressure relief control (change the hole size) states of the rock stress-strain curve. The test results show that with the change of pore diameter, the mechanical parameters of the characteristic points of stress-strain curves of rock samples in the whole process of uniaxial compression test under different borehole pressure relief control conditions are different. According to the specific parameters, the analysis part will be expanded.

With regard to the rock samples under the pressure relief regulation by drilling (in which the rock samples under the natural state are taken as the intact rock samples under the water softening regulation for blank comparative analysis), when the hole diameters of the rock samples are $0 \mathrm{~mm}$, $10 \mathrm{~mm}$, and $16 \mathrm{~mm}$, respectively, the average peak strength is 28.20 MPa, 25.06 MPa, and 16.57 $\mathrm{MPa}$, respectively. The average peak strain is $0.02127,0.02597$, and 0.01969 . The average elastic modulus was $2.42 \mathrm{GPa}, 0.86 \mathrm{GPa}$, and 1.27 $\mathrm{GPa}$, respectively. Compared with the natural intact rock samples, the average peak strength was reduced by $11.1 \%$ and $41.2 \%$, respectively. The average peak strain increased by $22.1 \%$ and decreased by $7.4 \%$ respectively. The mean modulus of elasticity decreased by $64.6 \%$ and $47.5 \%$, respectively. 


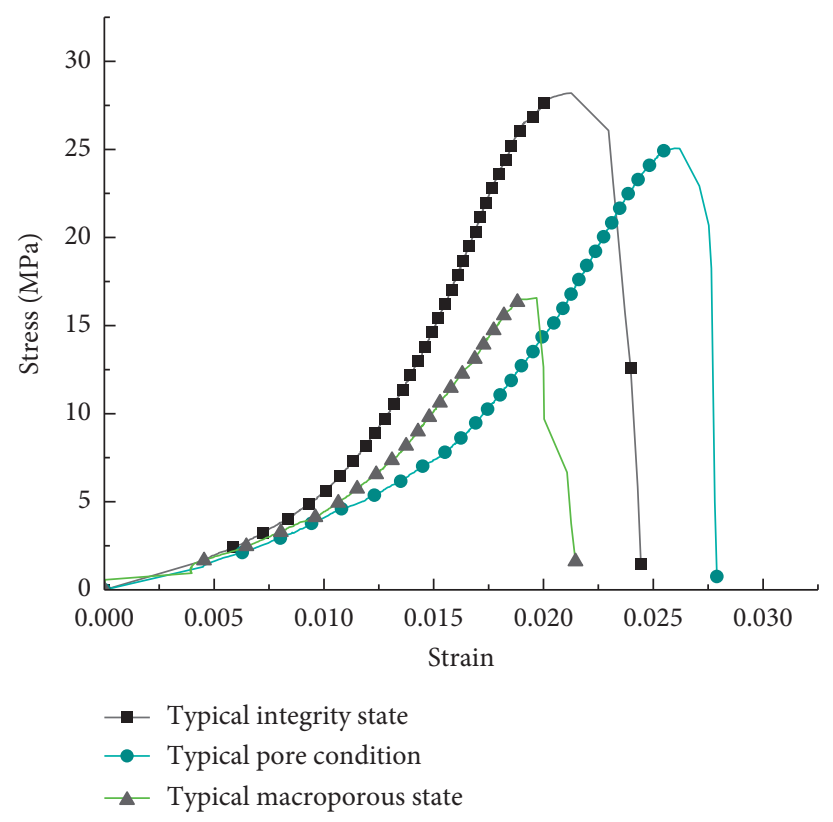

FiguRE 5: Stress-strain curves of rock samples with different pore sizes.

The comparative test results show that, with the increase of the hole size, the peak strength of the rock sample continues to decrease, and the amplitude increases significantly with the increase of the hole size. In addition, the peak strain presents a periodic change; that is, it first increases and then decreases; the elastic modulus presents a similar rule; that is, it first decreases and then increases.

Compared with the rock samples in the natural intact state, the peak strength of the rock samples controlled by borehole unloading decreases. However, with the change of borehole diameter, the mechanical parameters of the characteristic points in the stress-strain curve of the whole process change significantly; that is, the failure strain corresponding to small pore diameter increases, while the failure strain corresponding to large pore diameter decreases [13]. The reason is that stress adjustment is required in the bearing capacity of the rock samples containing holes. The small-bore rock samples are sufficient for stress adjustment, and large strain is formed in the process of stress adjustment. However, there is no time for the large-bore rock samples to undergo large stress degree adjustment, and the overall failure occurs, corresponding to the reduction of the failure strain $[14,15]$. Due to the existence of holes, the initial damage of the rock samples containing holes is increased and the strong brittleness is reduced. However, due to the man-made structure of the failure surface, all the failure cracks intersect in the hole area, which plays a certain role of directional dredge release.

3.2. Analysis of Failure Modes of Rock Samples under Different Modification States. In this test, uniaxial compression tests were carried out on rock samples with strong bursting liability under different modified states, and their failure modes were analyzed. In order to compare the differences of different modification measures, this paper analyzes the following three different modification measures.
3.2.1. Water Injection and Softening Regulation. As the mechanical properties of rock samples change with the change of water content, the failure modes of rock samples with different water content are also different after loading. The failure process of rock samples with different water content was recorded as a video, and the failure pattern of rock sample was identified and analyzed [16].

According to the test results, with the increase of water content, the peak strength of water action of the rock sample decreases, and under the influence of end effect, obvious shear failure occurs to the rock sample. In the state of high water content, the end effect is obvious, the rock sample is deformed greatly, the stress state is complex, the shear action is strong, and the rock mass is severely damaged. After the failure, the $\mathrm{x}$-shaped shear form with complex morphology is produced $[17,18]$. Uniaxial compression failure modes of rock samples under different water-bearing conditions are shear, and obvious shear cracks appear after failure. The rock samples in the dry state were destroyed in the form of a single shear, while the rock samples in the natural state and the saturated state were destroyed in the form of an $\mathrm{X}$-shaped shear. Moreover, with the increase of water content, the failure forms of the rock samples tended to be complicated.

3.2.2. Borehole Pressure Relief Control. Because the mechanical properties of rock samples change with the change of pore shape, the failure modes of rock samples with different pore sizes are also different after loading. The failure process of rock samples with different hole sizes was recorded as a video, and the failure patterns of rock samples were identified and analyzed.

According to the test results, the failure form of the rock samples containing holes is $x$-shaped conjugate shear failure, and the failure degree is quite intense (producing huge 
sound) during the laboratory test. The main failure surface of the rock samples develops along the diagonals of the rock samples and eventually intersects at the periphery of the holes [19-23]. It can be seen that the damage pattern is mainly affected by the holes.

\section{The Energy Evolution Law of Rock Samples under Different Modification Regulation Measures}

4.1. Energy Theory. Based on the broad consensus of the formation of rock burst induced by energy release, the energy principle is generally applied to the analysis of the evolution law of rock-bearing energy [24]. Taking uniaxial compression of a standard rock sample as an example, it is assumed that there is no heat exchange in the whole process; that is, the work carried out by compression load on the rock sample is absorbed by the rock sample itself, and the total stress variable of absorption is denoted as $U$. In addition, the energy storage properties of rock samples have also been tested and verified by many scholars. Therefore, most of the energy is stored in the released elastic strain energy $U^{e}$, while the remaining small amount of energy is dissipated in the form of dissipated strain energy $U^{d}$ and generates damage and deformation through bearing rock samples at the macro level, which can be expressed as $[25,26]$

$$
U=U^{e}+U^{d} \text {. }
$$

The total strain energy absorbed by bearing rock samples can be expressed as

$$
\begin{aligned}
U & =\int \sigma_{1} \mathrm{~d} \varepsilon_{1}=\sum_{i=0}^{n} \frac{1}{2}\left(\varepsilon_{1 i+1}-\varepsilon_{1 i}\right)\left(\sigma_{1 i}+\sigma_{1 i+1}\right), \\
U^{e} & =\frac{1}{2} \sigma_{1} \varepsilon_{1}^{e} .
\end{aligned}
$$

According to Hooke's law,

$$
U^{e}=\frac{1}{2} \sigma_{1} \varepsilon_{1}^{e} \approx \frac{\sigma_{1}^{2}}{2 E_{0}} .
$$

4.2. Energy Distribution Characteristics of Rock Samples under Different Modification Measures. In this experiment, uniaxial compression tests were carried out on rock samples with strong bursting liability under different modified states, and the energy evolution law was analyzed. Firstly, the energy distribution characteristics of natural intact rock samples were drawn. In addition, in order to compare the differences of different modification measures, this paper analyzed the following three different modification measures.

4.2.1. Typical Natural Intact State. Figure 6 shows the relationship between stress, energy, and strain in natural state under uniaxial conditions of rock samples. The loading process of bearing rock samples goes through five stages: the initial compaction stage (OA), elastic deformation stage $(\mathrm{AB})$, plastic deformation stage $(\mathrm{BC})$, yield failure stage $(\mathrm{CD})$, and late failure stage (DE).

4.2.2. Waterflood Softening Regulation. Figure 7 shows the relationship between stress, energy, and strain in the dry and saturated conditions of rock samples under uniaxial conditions. Compared with the typical natural state curve, the energy evolution curve shows that in different stages of stress-strain curve (previously explained), the energy components of rock samples with different water content show corresponding changing characteristics with different stages. The specific differences are as follows: in the dry state, the curve of dissipated energy density slowly rises after a falling inflection point. Under natural and full water state, the dissipated energy density curve rises sharply after a significant downward trend.

4.2.3. Borehole Pressure Relief Control. Figures 8 and 9 show the relationship between stress, energy, and strain under the condition of small pore size and large pore size under the condition of uniaxial rock sample. Summarizing the evolution of energy curve, with the stress-strain curve of different stages, namely, the consolidation stage, elastic stage, and yield and failure stage, different aperture change characteristics of the energy content of the present sample, the state of small aperture and nature and large pore size, and elastic energy curve of the sample composition were found; an essential difference was found between the small aperture state, and the elastic energy density curve is higher than the total strain energy curve. The elastic energy density curve is lower than the total strain energy curve under the natural and large aperture conditions.

4.3. The Energy Evolution Law of Rock Samples under Different Modification Measures. It is shown that, under the natural state of a complete typical sample, a significant initial pressure dense phase (OA), under the present trend of concave, and the phase relationship and the strain energy density characterization for nonlinear increase, due to the existence of natural random microcracks, lead to the early loading strain energy dissipation rate being greater than the elastic strain energy; this is because, at the initial deformation stage, the microcracks in rock mass close and friction consumes the most energy; stepping into the stage of elastic deformation $(\mathrm{AB})$, the stage of the basic present linear stressstrain curve changes, so the period of elastic strain energy begins to become dominant, and the total strain energy and the elastic strain energy are started with the increase of strain characterization for the constant growth of change, dissipation strain energy growth slowed down obviously, the microcracks of the sample closed, and the sample began to store energy, so the phase input into a sample of a considerable part of contribution of the whole strain energy of 


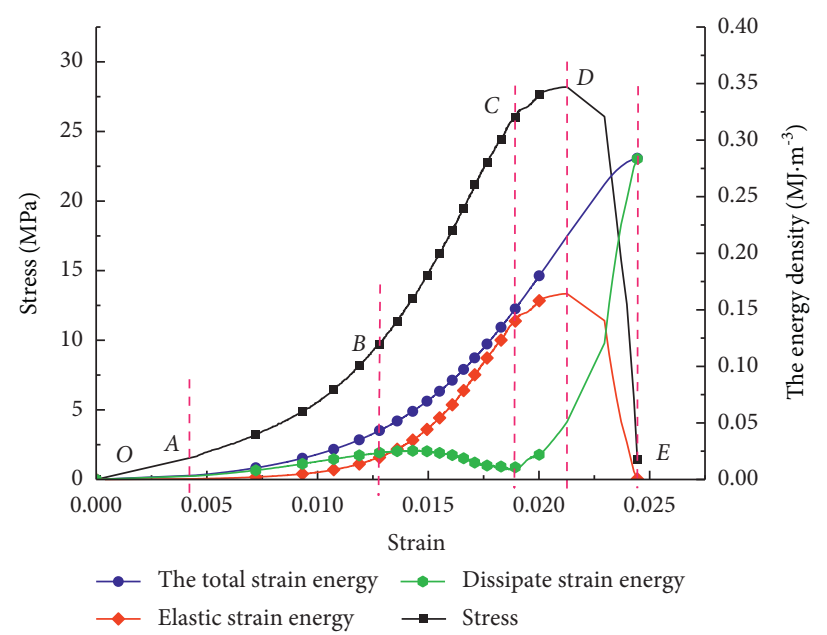

Figure 6: Energy density curves of typical natural rock samples.

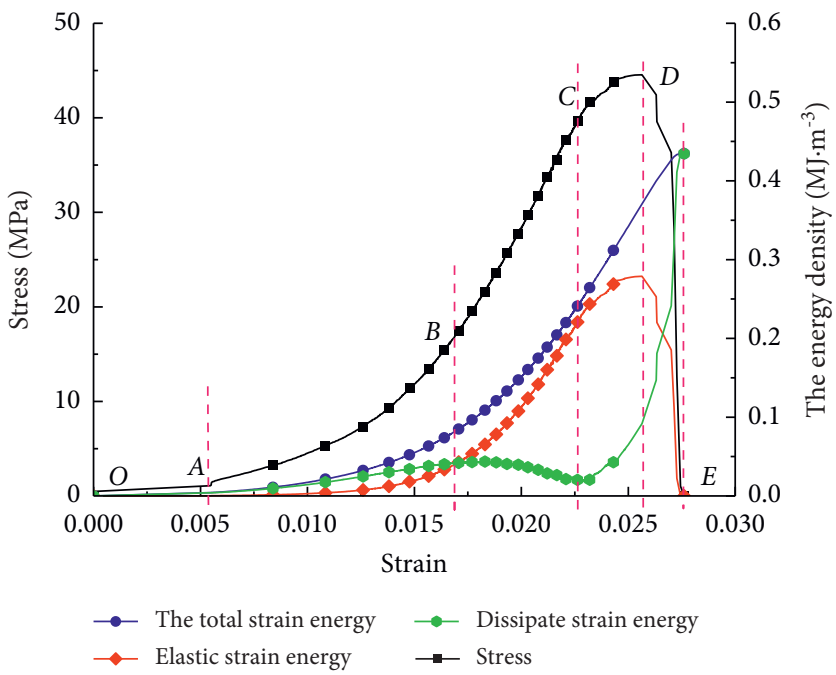

(a)

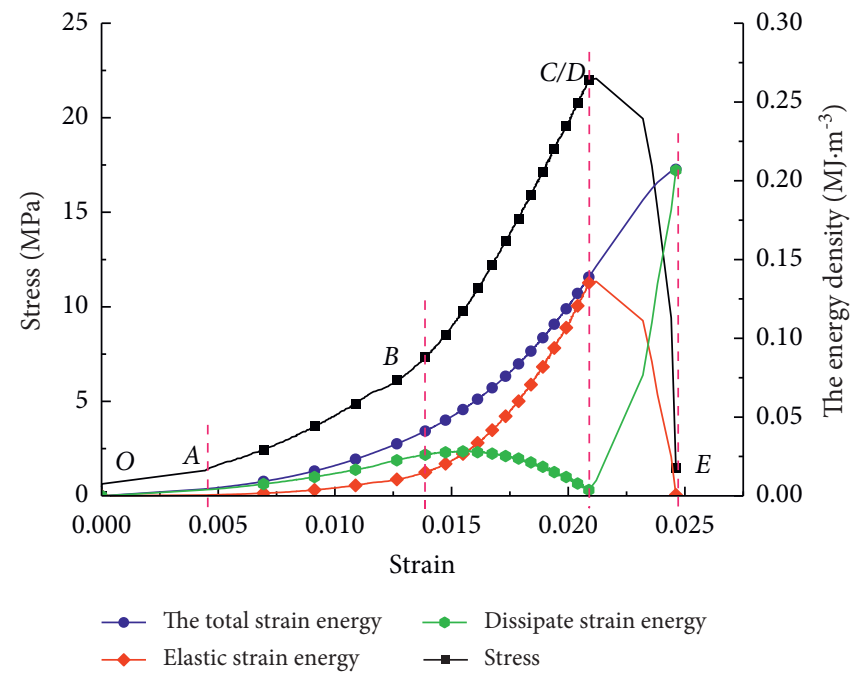

(b)

Figure 7: Relationship between stress, energy, and strain of rock samples under uniaxial conditions of different water-bearing states. (a) Energy density curves of rock samples under typical dry conditions. (b) Energy density curves of rock samples under typical saturated conditions.

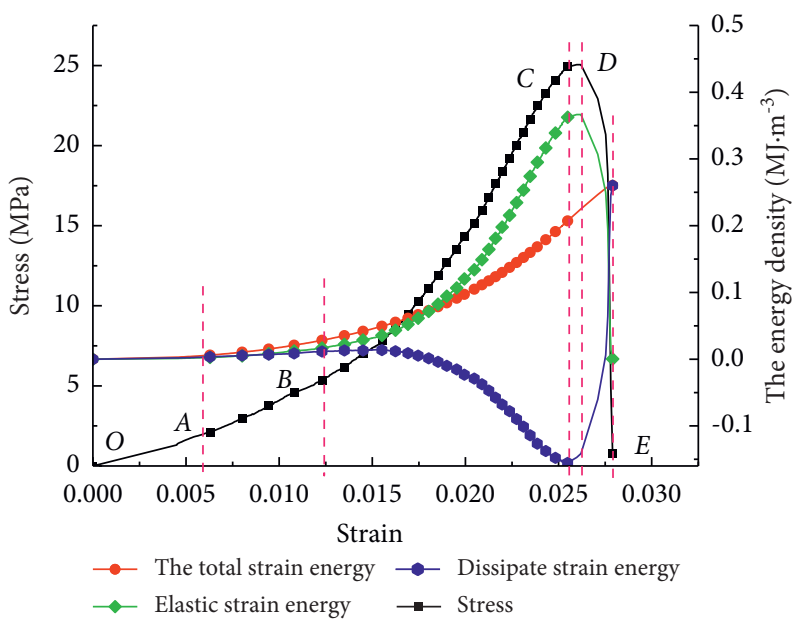

FIGURE 8: The relationship between stress, energy density, and strain under the uniaxial condition of rock sample with small pore size. 


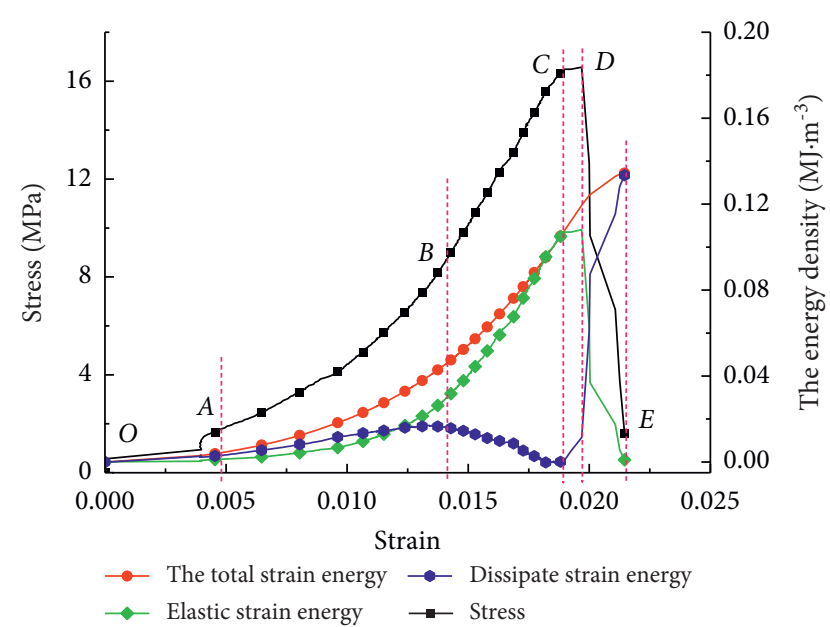

Figure 9: The relationship between stress, energy density, and strain under the uniaxial condition of rock sample with large pore size.

elastic strain energy and dissipation strain can be stable within a certain range. The plastic deformation stage (BC) had a significant linear relationship of the stress-strain curve, so the elastic strain energy stage obviously become dominant, as in the process of uniaxial compression, strain increases further, the total strain energy and elastic strain energy continue to increase, but the elastic strain energy rapidly grow, and the yield strength point reaches the elastic strain energy maxima (energy storage limit value); in this stage, dissipated strain energy decreases rapidly from the original stable state, and the curve of dissipated strain energy presents an obvious trend of "sinking," which is in good correspondence with the "energy storage period" of brittle rock before failure. With the continuous development of deformation, all the microcracks existing in the brittle rock sample at this time are closed with good integrity, constantly exerting their energy storage characteristics. In the yield failure stage (CD), after the yield strength point to the peak strength point, the damage degree of the rock sample increases rapidly, so the dissipated strain energy increases rapidly, so the stored elastic strain energy decreases slowly with the stress drop. The number of microcracks is increasing because new microcracks are generated gradually in this stage. In the later stage of failure (DE), after the peak strength point, the releasable elastic strain energy stored before the peak is released rapidly; that is, the dissipated strain energy increases rapidly and the elastic strain energy decreases rapidly. At this stage, the postpeak releasable elasticity can be released through macroscopic cracks, accompanied by kinetic energy and other forms.

\section{Analysis of the Energy Regulation Mechanism of Rock Samples under Different Modification Measures}

5.1. "Release First + Then Weaken" Energy Regulation Mechanism of Water Injection Softening Measures. With the increase of water content, the stress-strain curve of the rock sample in the uniaxial compression test has an overall trend of left-shift compression. The crack of water molecules is due to the weakened cohesion between particles, which leads to rock softening, further reduces the peak strength and elastic modulus of the rock sample, and decreases the macroperformance for the overall mechanical properties, and due to the particularity of hard rock, the properties of the brittle failure are kept, so the peak strain has a negative correlation. However, the brittleness of rock samples also reduces the proportion of yield failure stage, which brings certain risks to the accurate prediction of field engineering.

\section{2. "Release First + Guide Later" Energy Regulation Mecha-} nism of Borehole Pressure Relief Measures. As far as pore conditions are concerned, compared with intact rock samples, drilling will inevitably lead to a significant reduction in peak strength and peak strain of pore rock samples. From the pre-peak stage of stress-strain curve alone, the elastic energy stored before the peak of porous rock samples decreases. This method is in line with the idea (releasing energy) to control the pressure relief of rock burst, but the energy storage threshold of the material itself is inevitably lowered due to the artificially constructed weak surface. At the same time, due to the brittle characteristics of materials, the post-peak failure energy is sharply reduced, and the overall severity of failure is aggravated. Under certain conditions, it is very easy to produce rapid energy release, which is characterized as rock burst. This does not match with the idea of managing impact pressure temporarily.

\section{Conclusions}

For the study of mining under the action of a strong shock tendentiousness rock energy regulatory mechanism, based on the indoor rock mechanics experiment, the energy dissipation law of rock samples under different modification control measures is analyzed. The energy evolution mechanism of in situ modification of strong bursting liability roof rock samples is revealed, which provides ideas for the final rational combination of different modification regulation measures. The main conclusions are as follows:

(1) The physical and mechanical parameters of rock samples changed correspondingly under different modification regulation measures. Compared with the control group, the average peak intensity decreased by $36.7 \%$ and $50.5 \%$, respectively. The average peak strain decreased by $17.0 \%$ and $17.3 \%$, respectively. The average modulus of elasticity decreased by $32.0 \%$ and $49.7 \%$, respectively. Compared with the control group, the average peak strength of the rock sample decreased by $11.1 \%$ and $41.2 \%$, respectively. The average peak strain increased by $22.1 \%$ and decreased by $7.4 \%$, respectively. The mean modulus of elasticity decreased by $64.6 \%$ and $47.5 \%$, respectively. 
(2) The whole sample process was under different modification measures of the stress-strain curve such as the initial stage, stage of elastic deformation and plastic deformation stage, yield failure stage, and late stage, while the proportion of each stage under different modification measures is not the same, and the yield failure stage and late stage were focused on. In addition, the energy evolution law of the whole process is also different, especially in the yield failure stage and the later stage of the failure, and the yield failure stage provides favorable conditions for the accurate prediction of rock burst.

(3) The sequence of rock sample bursting tendency under different modification regulation measures was compared and analyzed to further explain the energy regulation mechanism of "release first + then weaken" water injection softening measure and "release first + then guide" hole pressure relief measure. In addition, it is important to consider the extreme value of strength deterioration and the reduction of yield failure stage faced by water injection softening measures. At the same time, it is necessary to consider the problem of increasing axial deformation caused by unreasonable hole size in borehole pressure relief measures. To sum up, gradient pressure relief scheme can be considered to avoid large stress drop caused by large-scale pressure relief in the region and further aggravate the instability of rock mass.

\section{Data Availability}

The data used to support the findings of this study are available from the corresponding author upon request.

\section{Conflicts of Interest}

The authors declare no conflicts of interest.

\section{Acknowledgments}

This research was funded by the Datong City Key R\&D Program Project (2019026) and 2019 Ministry of Education's first batch of industry-university cooperation collaborative education project (201901235007).

\section{References}

[1] H. Xie, L. Wu, and D. Zheng, "Prediction on the energy consumption and coal demand of China in 2025," Journal of China Coal Society, vol. 44, no. 7, pp. 1949-1960, 2019.

[2] Q. H. Qian, "Definition mechanism classification and quantitative forecast model for rockburst and pressure bump," Rock and Soil Mechanics, vol. 35, no. 1, pp. 1-6, 2014.

[3] L. Yuan, "Research progress on risk identification assessment monitoring and early warning technologies of typical dynamic hazards in coal mines," Journal of China Coal Society, vol. 45, no. 5, pp. 1557-1566, 2020.
[4] G. Liu, Y. Chen, and X. Du, "Investigation of microcrack propagation and energy evolution in brittle rocks based on the voronoi model," Materials, vol. 14, no. 9, 2021.

[5] Y. Wang, S. H. Gao, and C. H. Li, "Energy dissipation and damage evolution for dynamic fracture of marble subjected to freeze-thaw and multiple level compressive fatigue loading," International Journal of Fatigue, vol. 142, 2021.

[6] Y. Tian, R. Yu, and Y. Zhang, "Research on damage evolution of deep formation rock based on acoustic emission test," International Journal of Damage Mechanics, vol. 30, no. 1, 2021.

[7] H. Zhang, X. Zhang, and H. Zhou, "Research on acoustic emission characteristics and constitutive model of rock damage evolution with different sizes," Advances in Civil Engineering, vol. 2020, Article ID 6660595, 8 pages, 2020.

[8] Y. Li, Y. Zhao, and J. Tang, "Rock damage evolution model of pulsating fracturing based on energy evolution theory," Energy Science \& Engineering, vol. 8, no. 4, 2020.

[9] N. Fedotov, "Rock damage evolution as failure process of hierarchical structure," Physics of the Earth and Planetary Interiors, vol. 301, 2020.

[10] H. Han, D. Fukuda, and H. Liu, "FDEM simulation of rock damage evolution induced by contour blasting in the bench of tunnel at deep depth," Tunnelling and Underground Space Technology incorporating Trenchless Technology Research, vol. 103, 2020.

[11] S. N. Fedotov, "Rock damage evolution as failure process of hierarchical structure," Physics of the Earth and Planetary Interiors, vol. 301, 2019.

[12] L. Qi, Q. Liu, and Y. Pan, "Experimental study on rock indentation using infrared thermography and acoustic emission techniques," Journal of Geophysics and Engineering, vol. 15, no. 5, 2018.

[13] R. Geranmayeh Vaneghi, K. Thoeni, A. V. Dyskin, M. Sharifzadeh, and M. Sarmadivaleh, "Strength and damage response of sandstone and granodiorite under different loading conditions of multistage uniaxial cyclic compression," International Journal of Geomechanics, vol. 20, no. 9, Article ID 04020159, 2020.

[14] V. Srinivasan, T. Gupta, T. A. Ansari, and T. N. Singh, "An experimental study on rock damage and its influence in rock stress memory in a metamorphic rock," Bulletin of Engineering Geology and the Environment, vol. 79, no. 8, pp. 4335-4348, 2020.

[15] J. H. Liu, W. L. Yang, F. X. Jiang, and X. S. Guo, "Mechanism of cracking-before-injecting method to prevent coal burst and its field test," Chinese Journal of Rock Mechanics and Engineering, vol. 36, no. 12, pp. 3040-3049, 2017.

[16] S. Liu, M. Feng, J. Pan, and S. Wang, "Experimental analysis on vibration of roadway with strong probability of rockburst subjected to pressure relief blasting," Chinese Journal of Rock Mechanics and Engineering, vol. 35, no. 5, pp. 906-918, 2016.

[17] Y. Zhang, X. M. Sun, Y. L. Zheng, J. B. Li, Z. B. Guo, and B. Zhang, "An anti-punching and energy-releasing coupling support technology in deep mining roadway and its application," Chinese Journal of Rock Mechanics and Engineering, vol. 38, no. 9, pp. 1860-1869, 2019.

[18] B. Bahmani, R. Abedi, and P. Clarke, "A stochastic bulk damage model based on mohr-coulomb failure criterion for dynamic rock fracture," Applied Sciences, vol. 9, no. 5, 2019.

[19] Q. Wu, X. Li, M. Tao, and F. Zhao, "Conventional triaxial compression on hollow cylinders of sandstone with various fillings Relationship of surrounding rock with 
support," Journal of Central South University, vol. 25, no. 8, pp. 1976-1986, 2018.

[20] S. Levasseur, H. Welemane, and D. Kondo, "A microcracksinduced damage model for initially anisotropic rocks accounting for microcracks closure," International Journal of Rock Mechanics and Mining Sciences, vol. 77, pp. 122-132, 2015.

[21] S. He, D. Song, X. He et al., "Coupled mechanism of compression and prying-induced rock burst in steeply inclined coal seams and principles for its prevention," Tunnelling and Underground Space Technology, vol. 98, 2020, https://www.sciencedirect. com/science/article/abs/pii/S088677981930851X.

[22] F. Jiang, G. Yang, Q. Wei, and C. Wang, "Study and prospect on coal mine composite dynamic disaster real-time prewarning platform," Journal of China Coal Society, vol. 43, no. 2, pp. 333-339, 2018.

[23] H. Xie, Y. Ju, M. Gao, and F. Gao, "Theories and technologies for in-situ fluidized mining of deep underground coal resources," Journal of China Coal Society, vol. 43, no. 5, pp. 1210-1219, 2018.

[24] W. Liang, Y. Zhao, and S. Xu, "Study on the theory of in-situ solution minin," Journal of Taiyuan University of Technology, vol. 43, no. 3, pp. 382-387, 2012.

[25] H. Xie, R. Peng, and Y. Ju, "Energy dissipation of rock deformation and fracture," Chinese Journal of Rock Mechanics and Engineering, vol. 23, no. 21, pp. 3565-3570, 2004.

[26] L. Zhang, G. Wang, and L. E. I. Ruide, "Study on energy damage evolution mechanism of single fractured rock mass with different length under uniaxial compression," China Journal of Highway and Transport, pp. 1-11, 2020. 